\title{
Pre-Service Teacher Education: Student Digital Technology Skills for Best Practice in the STEM Classroom
}

\author{
Michelle Mukherjee \\ Queensland University of Technology
}

\author{
Shaun Nykvist \\ Norwegian University of Science and Technology \\ Christopher Blundell \\ Queensland University of Technology
}

\begin{abstract}
This paper explores digital technology skills in commencing undergraduate pre-service teachers at a large Australian metropolitan university by surveying all first year students over a period of eight years $(n=2821)$. The survey gathered self-reported data using Likert-scale questions and this was analysed using descriptive statistics. It was found that the technological skills of many of the students was lower than that assumed by tertiary educators. Additionally, there was no evidence of an increase in the general technological skills in commencing students over the 2012 to 2019 period. These findings have implications for the design of units in pre-service teacher STEM courses.
\end{abstract}

Keywords: digital technology skills, teacher education, STEM

\section{INTRODUCTION}

There is no doubt that the role of the educator is a complex one influenced by many factors ranging from policy development to the role of innovative and transformative practice incorporating digital technologies. Digital technologies are defined in this paper as being software and hardware used to conduct internet searches; analyse and display data; communicate (including creating and editing audio/video); visualise through Augmented or Virtual Reality (AR or VR) and collect data e.g., drones. There is a need for teachers to not only understand the role of digital technology to solve problems and act as a catalyst for emerging practices in the STEM classroom, but to also ensure that their students have the access and capabilities to use them when and where they are needed. While these tools afford educators and their students many opportunities, there are often factors or barriers that can impede their effective use within the learning process (see Hennessy and Onguko, 2010). Pre-service teachers can have pre-defined beliefs about the use of digital technologies and a range of digital capabilities that are often self-assessed at varying levels. This has wide-ranging implications for the design of programs of study and pedagogical approaches that can adequately prepare students for their future roles as STEM educators. It is within this context that there is a paucity of research with regards to the preparation of pre-service teachers (PST) and the adequate 
development of their digital capabilities through innovative programs of study. This paper highlights the findings from an eight year study that investigates the digital technology skills that students bring with them into pre-service education and draws upon these findings to recommend a more flexible and responsive approach to the development of pre-service STEM educators.

\section{LITERATURE REVIEW}

Several studies have highlighted the discrepancies between students' knowledge of digital technology when entering pre-service teacher education (Blackley \& Walker, 2017; Seifert, 2015) and the influences that these mixed abilities and pre-conceptions about digital technology can have on how they develop as educators. Blackley and Walker (2017) report that pre-service teachers who used 1:1 laptops in their schooling were familiar with a limited range of technologies on entry to university: Word and Powerpoint, internet research, email and accessing learning management systems. Seifert (2015) found that PST were "sceptical and somewhat reluctant to use smartphones in their classes" (p. 9), while Poyo (2016) claims that some PST's negative experiences using digital technologies while at school can negatively influence their attitudes to using digital technologies in tertiary study and while undertaking practicum experiences. More recently, McGarr and McDonagh (2021) noted that pre-service teachers entering a programme in Ireland while being very frequent users of social media, self-reported lower skills in other digital technologies, and indeed poor levels of ability with video creation and editing. A similar study in Turkey (Çebi \& Reisoğlu, 2020) found that digital content creation and problem solving were self-scored low in a survey of their pre-service teachers' ICT skills, though communication and collaboration was self-scored high.

As educators of pre-service teachers, there is a need to address these issues and ensure that our current students and future generations have the capabilities and a range of durable skills to apply in the STEM classroom, to not only survive but to also progress in new times. In Australia, this mandate arises from curriculum documents:

To participate in a knowledge-based economy and to be empowered within a technologically sophisticated society now and into the future, students need the knowledge, skills, and confidence to make ICT work for them at school, at home, at work and in their communities. Information and communication technologies are fast and automated, interactive, and multimodal, and they support the rapid communication and representation of knowledge to many audiences and its adaptation in different contexts. They transform the ways that students think and learn and give them greater control over how, where and when they learn. (Australian Curriculum, Assessment and Reporting Authority [ACARA], 2013, para. 2)

This is also reflected internationally in ISTE Standards for Students: "Students critically curate a variety of resources using digital tools to construct knowledge, produce creative artifacts and make meaningful learning experiences for themselves and others" (International Society for Technology in Education [ISTE], 2021, Knowledge Constructor) and "Students develop and employ strategies for understanding and solving problems in ways that leverage the power of technological methods to develop and test solutions" (International Society for Technology in Education [ISTE], 2021, Computational Thinker).

The development of curriculum needs to be set within a framework that allows flexibility and growth for students. It needs to be future driven, but it must also address the many current challenges faced by today's students. Innovation in the areas of STEM education needs a responsive curriculum and educators who can respond to a rapidly changing globalised world. Karno and Glassman (2013) discuss how access to the internet allows a new classroom space in which as collective intelligence is built. STEM learning can be grounded in situated cognition theory (Lave \& Wenger, 1991), which recognises that the physical and social contexts of a learning activity are critical to the learning process. Project-based learning tasks often begin with a research phase that is enabled by the internet (Howland et al., 2011), and easy access to the 
internet via mobile devices allows STEM inquiry to happen anytime and anywhere. STEM students and teachers need the search skills and the ability to leverage the affordances of digital tools to obtain timely information at different project stages.

Examples of ways in which technologies can enhance learning in STEM include the use of digital media (e.g., photographs, video and audio), which can provide alternative ways of documenting STEM activities to the traditional laboratory report. They can allow students who have strong STEM understandings, but weak written skills to gain credit for their knowledge by speaking their explanations rather than writing them. Digital media can also be collated as ePortfolios that can be used for formative and summative assessment (Newhouse, 2015). Visualisation tools in STEM learning can include visualising data in the form of graphs or charts using spreadsheets, or visualising systems and processes using simulations or virtual reality. Augmented reality (AR) can add a contextual layer of information to a real-world image (Azuma, 1997) using 3D technology which merges physical and digital worlds in real time (Ibáñez \& Delgado-Kloos, 2018). There are increasing numbers of free or relatively cheap apps for smartphones and tablets, which makes this technology accessible in the school or university classroom. Many of the augmented reality apps that can be used in STEM education offer exploration or simulation activities. A study by Yoon et al. (2017) showed that students using AR showed greater knowledge gains in STEM compared to students learning the same topic without AR, while a study by Loong and Herbert (2018) claimed that blogs and wikis can allow peers in the STEM classroom to comment on one another's processes, analyses and conclusions in schools.

\section{RESEARCH DESIGN}

The research presented here is an exploratory case study (Yin \& Campbell, 2018) designed to understand the digital technology background of students entering a pre-service teacher education program between 2012 and 2019 (eight years). More specifically the research draws upon the students' past and current experiences in a core digital technologies unit and their expectations towards using digital technologies in their future teaching. The pre-service teacher cohort $(n=2821)$ consists of a mixture of early childhood, primary and secondary pre-service teachers. The research was a mixed method research design consisting of both qualitative and quantitative data, though this paper is largely focussed on the quantitative data. Students were asked to voluntarily complete an anonymous online survey at the beginning of the semester.

The survey asked students their age range and then asked to self-report about their experience level with a range of technology skills. The categories were taken from the literature which outlines activities using technology that are useful in STEM learning and teaching. The questions were piloted in 2012 and were refined over the subsequent years. While the main body of questions remained the same, new questions were added as new technologies became more ubiquitous in classrooms. Although, the students were selfreporting their skills, tutors were able to observe the level of skills observed in the classes to compare this with the survey data.

An example of the digital technology skills that students were asked to self-rate on a Likert scale of No Knowledge, Beginner, Some knowledge, Comfortable or Expert for the included:

- Using a web browser for searching (Internet Explorer, Firefox, Chrome, Safari or other)

- Backing up files to external media (USB or cloud storage)

- Backing up important data on your computer (including photos, and important files)

- Presentation Software (e.g., Powerpoint, Keynote, Prezi, Libre Office)

- Spreadsheet Software (e.g., Microsoft Excel, Apple Numbers, Libre Office)

- Word Processing (e.g., Microsoft Word, Apple Pages, Libre Office)

- Creating and editing photos

- Creating and editing video

- Creating and editing an audio file

- Transferring photos and video from one digital device to another e.g. phone to laptop

- Writing a blog 
- Writing a wiki

- Using AR or VR Technology

- Flying a drone or using robotics.

To reduce factors affecting reliability of survey data, the survey items were piloted on a group of five first year students using a think-aloud protocol so that their interpretation of the questions and the language used could be uncovered. Any necessary adjustments were then made to the language of the items. The data were analysed using descriptive statistics and the self-reported technology skills from the Likert scales were graphed for comparison.

\section{RESULTS AND DISCUSSION}

In $2019,87 \%$ of students were in the 17 to 22 age range when commencing their pre-service teacher course. This figure was $81 \%$ in the 2012 data and varies around these percentages each year. Figure 1 (below) shows the 2019 data set of students' responses to Likert scale questions asking them to self-assess their technological skills and knowledge in relation to a series of tasks $(n=618)$. Figure 2 shows the same data from an earlier 2015 survey $(n=303)$.

\section{FIGURE 1}

2019 STUDENT SELF-REPORTED TECHNOLOGY SKILL LEVELS (n=618)

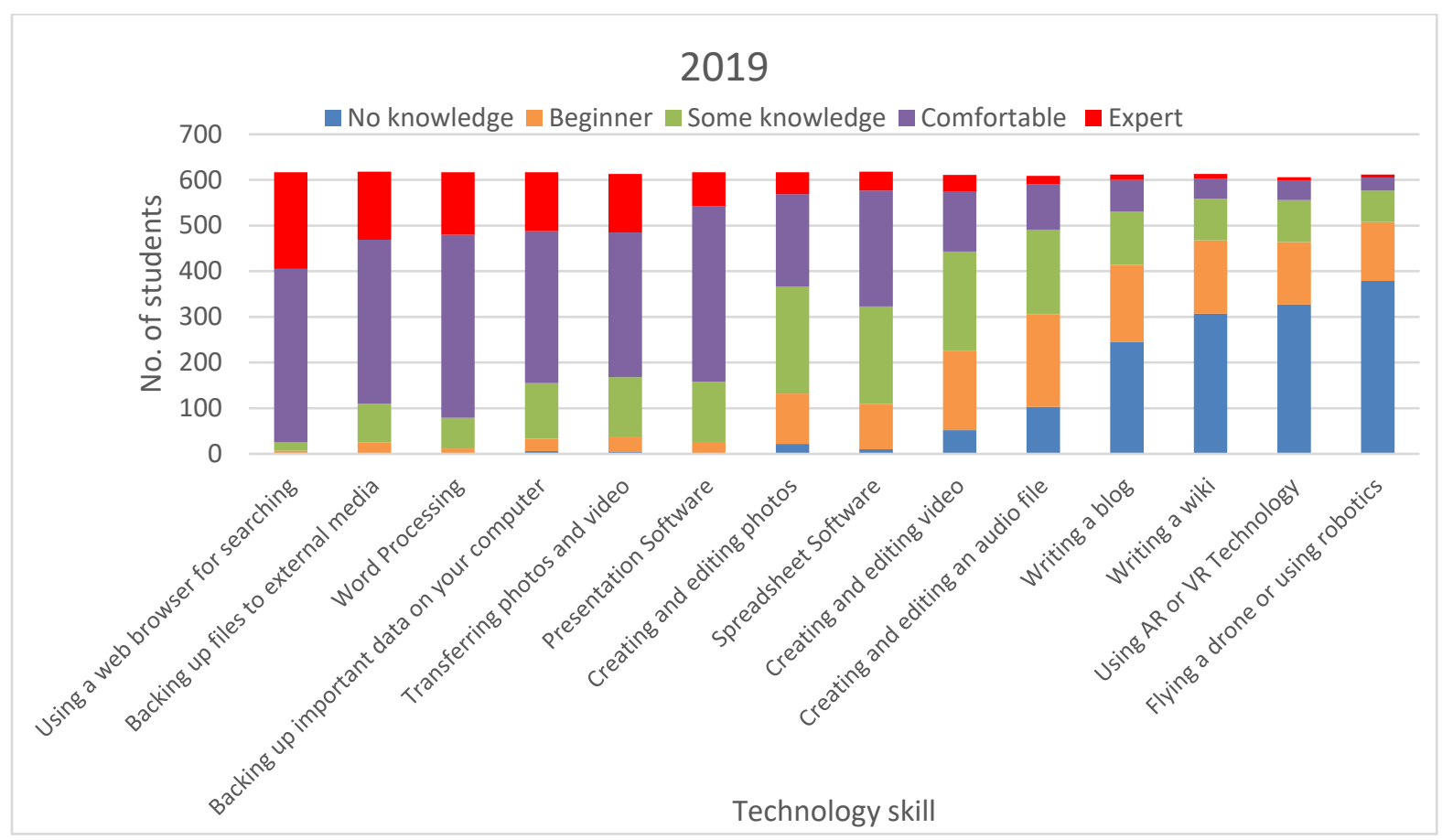




\section{FIGURE 2 \\ 2015 STUDENT SELF-REPORTED TECHNOLOGY SKILL LEVELS (n=303)}

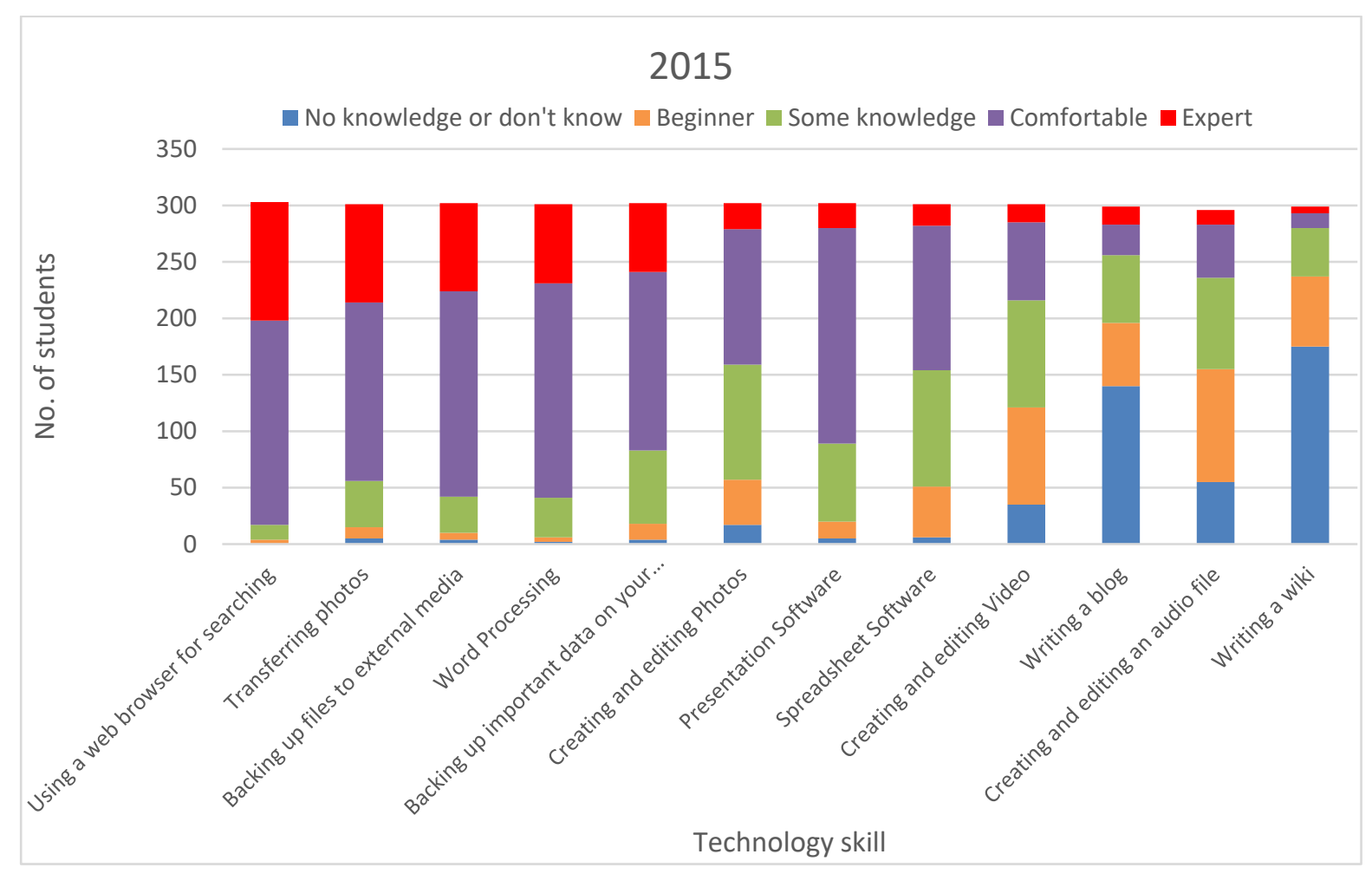

Unsurprisingly, in both years, students reported they were comfortable or expert in using web browsers ( $96 \%$ comfortable or expert users in 2019$)$ and being able to use backup systems for files $(82 \%$ comfortable or expert users in 2019). Given the ubiquity of (productivity) software in education and that approximately 80 to $90 \%$ of students were either straight from school or within a couple of years since leaving, it seems reasonable for tertiary educators to assume that students have a knowledge of the common word processing, presentation and spreadsheet software and to also expect students to use these to create reports, prepare presentations and analyse and display data respectively. Interestingly, for presentation software, $25 \%$ of students entering the PST courses in 2019 said they were beginners in using this or had a little knowledge, with $12.6 \%$ saying they were expert. This compares with $28 \%$ saying they were beginners or had some knowledge in the 2015 data and $7 \%$ saying they were expert. Table 1 shows the student self-reported skills in using presentation software from 2012 to 2019, suggesting that student self-reported skills have remained somewhat consistent over time, rather than increasing. This trend is reflected in the other technology skills, as can be seen by a comparison of the 2015 and 2019 data in Figures 1 and 2. Possible reasons for this could be due to the increase in complexity of the software over time, or greater self-awareness by students of their skill level (realising what they do not know). 


\section{TABLE 1 \\ STUDENT SELF-REPORTED SKILLS WITH PRESENTATION SOFTWARE FROM 2012 TO 2019}

\begin{tabular}{lllllllll}
\hline & & \multicolumn{7}{c}{ Year } \\
& 2012 & 2013 & 2014 & 2015 & 2016 & 2017 & 2018 & 2019 \\
\hline No. of PST respondents & 516 & 511 & 381 & 302 & 125 & 161 & 207 & 618 \\
$\begin{array}{l}\text { PST self-rated beginner or } \\
\text { some knowledge }\end{array}$ & $24 \%$ & $27 \%$ & $24 \%$ & $28 \%$ & $30 \%$ & $24 \%$ & $24 \%$ & $25 \%$ \\
PST self-rated expert & $15 \%$ & $17 \%$ & $16 \%$ & $7 \%$ & $9 \%$ & $12 \%$ & $9 \%$ & $13 \%$ \\
\hline
\end{tabular}

Spreadsheet software is central to analysis of data in school setting, in which data can be manipulated and visualized. However, as can be seen in Figure 1, 48\% of students said they had beginner or some knowledge of spreadsheet skills in 2019, with only $7 \%$ claiming to be expert in their use. This suggests that many students could be ill-equipped to be successful in the analysis activities in tertiary STEM subjects which involve spreadsheet skills, causing an impediment to their learning.

Video making skills can be utilized by STEM learners to document experiments and explain scientific concepts in a different format to the traditional laboratory report and examination / quiz. However, in 2019, $64 \%$ of students reported they were beginners / had some knowledge of video skills, with $6 \%$ claiming to be expert. This compares with $60 \%$ of students in the beginner / some knowledge category in 2015 and $5 \%$ in the expert category, again showing little change over time. The numbers were similar for creating and editing audio files. Teachers are being increasingly called upon to use video skills to create flipped learning resources, so these skills are important for the STEM classroom and beyond.

Wikis and blogs can be used in science to share results and comment on peers' experimental methods and conclusions. In 2019, 50\% of students reported no skills in writing a wiki. $47 \%$ of students were beginners or had a little knowledge of writing a blog while $40 \%$ had no knowledge. Other technologies for which a high proportion of students reported having no knowledge were flying a drone $(62 \%)$ and using augmented or virtual reality (54\%). These are emerging technologies in schools, but are becoming increasingly ubiquitous in STEM classrooms, to obtain aerial shots of data in inaccessible places e.g., for biological survey (drones) and other STEM activities (Carnahan, Crowley, Hummel, \& Sheehy, 2016); VR to visualize large (e.g., the solar system), small (e.g., atomic structures) or inaccessible systems (e.g., nuclear power plants), or to simulate labs (Ma, Xiao, Wee, Han, \& Zhou, 2014).

While it is not essential to master all the above technological skills to be an effective STEM educator / learner, there are benefits to be gained by having at least a working knowledge of these tools and how they can be used in teaching and learning to support both students and teachers. Currently, pre-service teacher courses might be assuming knowledge and skills that do not align with their students' actual competences. It follows that courses need to have a flexible and agile construction that is based around the needs of the entering students, and these needs are not often discovered before the students commence the course. This has been a driving factor in the implementation of this survey to PST to ensure that we better understand the digital technology skills and experiences that have shaped our current students. Tondeur et al. (2021) argue that personalization of learning processes is necessary when preparing pre-service teachers to use technology in educational practice. The design of the course should allow for personalized development in the areas of digital skills that students lack experience in, while acknowledging their strengths. Currently, finding the gaps in the PSTs' skills and associated knowledge allows academics to direct students to the existing resources within the university to address these, such as self-study videos and one on one or group coaching from the student support services. While this is a study of an initial teacher education course at one large Australian university, further research is needed to address the needs of PST as they enter university and to develop their digital technology skills. A rethink of pedagogical approaches used in the learning and teaching associated with these students, that better embraces and develop students' skills as well as new approaches to course design could be sued to improve the emerging needs of future STEM educators. 


\section{CONCLUSION}

Courses for pre-service teachers (PST) often assume that students have a certain level of digital technology skills, which can have an impact on these students' success in both learning and teaching STEM subjects. The data demonstrates that many school leavers are not skilled in the use of basic productivity software, and have very little experience or knowledge of emerging technologies such as virtual / augmented reality or robotic type technologies such as drones. The research data is not changing over time and school leavers are not entering university with greater (self-reported) skills in digital technologies. This has an impact on their learning of STEM subjects, and also affects the development of their STEM teaching skills. Identifying the gaps can allow tertiary educators to direct students to the appropriate help available in the institution and to adapt their pedagogical practices. This also supports the need for a more agile and flexible curriculum within preservice teacher education which is not pre-prescribed years before a student enters a course.

\section{REFERENCES}

Australian Curriculum, Assessment and Reporting Authority [ACARA]. (n.d.). Information and Communication Technology (ICT) Capability. Retrieved from https://www.australiancurriculum.edu.au/f-10-curriculum/general-capabilities/information-andcommunication-technology-ict-capability/

Azuma, R.T. (1997). A Survey of Augmented Reality. Presence: Teleoperators and Virtual Environments, 6(4), 355-385. doi:10.1162/pres.1997.6.4.355

Blackley, S., \& Walker, R. (2017). Pre-service teachers' reflections: The influence of school 1:1 laptop programs on their developing teaching practice. Australian Journal of Teacher Education, 42(2), $1-13$.

Carnahan, C., Crowley, K., Hummel, L., \& Sheehy, L. (2016). New perspectives on education: Drones in the classroom. Paper presented at the Society for Information Technology \& Teacher Education International Conference.

Çebi, A., \& Reisoğlu, İ. (2020). Digital Competence: A Study from the Perspective of Pre-service Teachers in Turkey. Journal of New Approaches in Educational Research (NAER Journal), 9(2), 294-308.

Hennessy, S., \& Onguko, B. (2010). Developing the Use of Information and Communication Technology to Enhance Teaching and Learning in East African Schools: Review of the Literature. Centre for Commonwealth Education \& Aga Khan University Institute for Educational Development Eastern Africa Research Report No. 1.

Howland, J.L., Jonassen, D., \& Marra, R.M. (2011). Meaningful Learning with Technology. Boston, MA: Pearson Education.

Ibáñez, M-B., \& Delgado-Kloos, C. (2018). Augmented reality for STEM learning: A systematic review. Computers \& Education, 123, 109-123. doi:10.1016/j.compedu.2018.05.002

International Society for Technology in Education [ISTE]. (2021). Retrieved from https://www.iste.org/standards/iste-standards-for-students

Karno, D., \& Glassman, M. (2013). Science as a Web of Trails: Redesigning Science Education with the Tools of the Present to Meet the Needs of the Future. Journal of Science Education and Technology, 22(6), 927-933.

Lane, J. (2015). A Multimodal Discourse on the Use of Touch Enabled Mobile Devices for Mathematics Education. In M. Meletiou-Mavrotheris, K. Mavrou, \& E. Paparistodemou (Eds.), Integrating Touch-Enabled and Mobile Devices into Contemporary Mathematics Education (pp. 214-240). Hershey, PA: IGI Global. doi:10.4018/978-1-4666-8714-1.ch010

Lave, J., \& Wenger, E. (1991). Situated learning: Legitimate peripheral participation. Cambridge, England: Cambridge University Press. 
Loong, E.Y-K., \& Herbert, S. (2018). Primary school teachers' use of digital technology in mathematics: The complexities. Mathematics Education Research Journal, 30(4), 475-498. http://dx.doi.org/10.1007/s13394-018-0235-9

Ma, T., Xiao, X., Wee, W., Han, C.Y., \& Zhou, X. (2014). A 3D virtual learning system for STEM education. Paper presented at the International Conference on Virtual, Augmented and Mixed Reality.

McGarr, O., \& McDonagh, A. (2021). Exploring the digital competence of pre-service teachers on entry onto an initial teacher education programme in Ireland. Irish Educational Studies, 40(1), 115128.

Newhouse, C.P. (2015). Using Digital Technologies to Improve the Authenticity of Performance Assessment for High-Stakes Purposes. Technology, Pedagogy and Education, 24(1), 17-33.

Poyo, S.R. (2016). Transforming traditional practices of teacher preparation to meet changing needs of digital learners: A first step intervention by assessing and addressing needs of pre-service teachers in a dual learning environment. Doctor of Education. Duquesne University.

Seifert, T. (2015). Pedagogical Applications of Smartphone Integration in Teaching: Lecturers, PreService Teachers and Pupils' Perspectives. International Journal of Mobile and Blended Learning, 7(2), 1-16. doi:10.4018/ijmbl.2015040101

Tondeur, J., Howard, S.K., \& Yang, J. (2021). One-size does not fit all: Towards an adaptive model to develop preservice teachers' digital competencies. Computers in Human Behavior, 116, 106659.

UNESCO. (2017). Developing and implementing curriculum frameworks. Retrieved from https://unesdoc.unesco.org/ark:/48223/pf0000250052 accessed on 23/02/2019

Yin, R.K., \& Campbell, D.T. (2018). Case study research and applications: Design and methods (Sixth edition). SAGE.

Yoon, S., Anderson, E., Lin, J., \& Elinich, K. (2017). How augmented reality enables conceptual understanding of challenging science content. Journal of Educational Technology \& Society, $20(1), 156$. 